American Journal of

Health, Medicine and Nursing Practice (AJHMN)

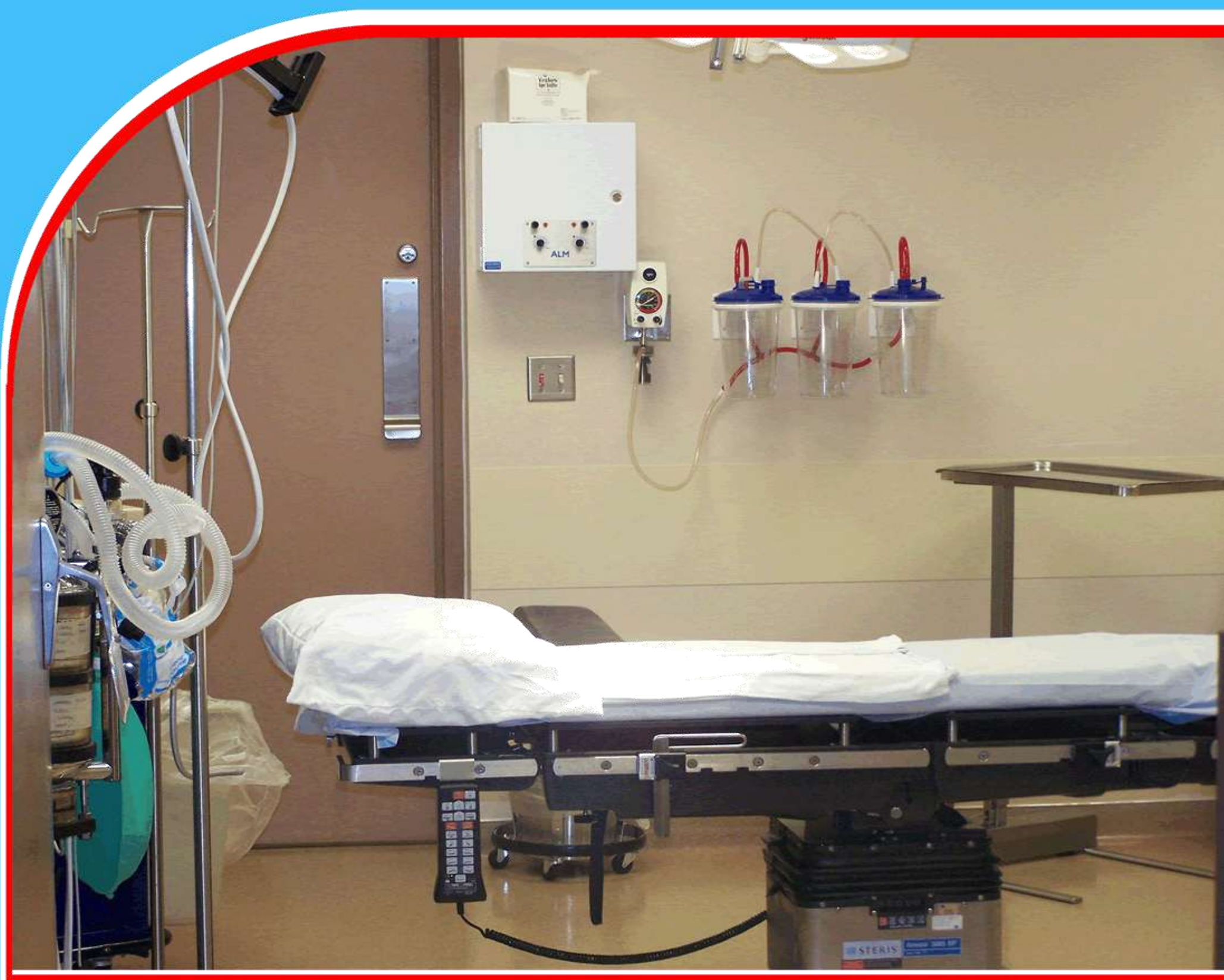

Perceptions of medical college academics on intercalated MBBS/BSc dual degree program in Nigeria.

Kani Yamuna Aminu Usman Ahmad Rehinat Nasir Adejumo

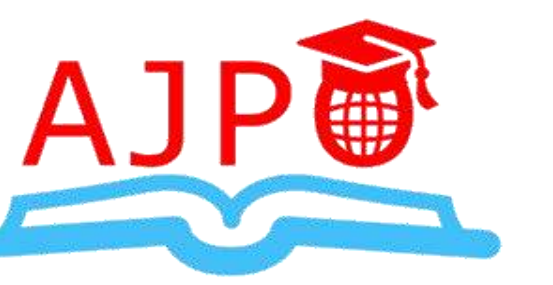




\title{
Perceptions of medical college academics on intercalated MBBS/BSc dual degree program in Nigeria
}

\author{
${ }^{1 *}$ Kani Yamuna Aminu \\ Senior Lecturer / consultant Department of Obstetrics and Gynaecology Faculty of clinical \\ sciences, College of Medicine and health sciences Federal University Dutse Jigawa state \\ Nigeria \\ yamuna.kani@fud.edu.ng
}

${ }^{2}$ Usman Ahmad

Associate professor Department of Internal Medicine College of Medicine and Health Sciences Federal University Dutse Jigawa State Nigeria

${ }^{3}$ Rehinat Nasir Adejumo

Consultant Obstetrician and Gynaecologist Department of Obstetrics and Gynaecology Rasheed Shekoni Teaching Hospital Dutse Jigawa State Nigeria

\begin{abstract}
Purpose: The purpose of this study was to determine the perceptions of academics on the acceptability of the intercalated medical degree program in an attempt to proffer solutions to breach the gaps in manpower shortages in the medical profession.

Methodology: This is a descriptive cross sectional survey. Randomly selected 150 academic staff of various medical colleges spread across Nigeria, who attended an educational programme in Abuja Nigeria in September 2018 completed semi structured questionnaires after consenting to participate in the study. Data from the retrieved questionnaires were collated, entered into Microsoft excel and analyzed using descriptive statistics. Most of the analyzed data were represented in percentages for ease of comparison.

Findings: Sixty five percent of the respondents were aware of the intercalated (dual) Bachelor of Medicine, Bachelor of Surgery (MBBS)/ Bachelor of Science (B.Sc.) degree programme, offer it in their institutions and believe it is worthwhile. The merits of the dual degree programme from this study were an additional degree, more experienced medical doctors in terms of research and exit strategy for some medical students who may change their minds half way into the medical programme. The disadvantages reported were prolonged study period and increased cost of study. Majority of the respondents, who were academic staff of medical colleges were aware of, and favoured the establishment of intercalated MBBS degree programme in more Nigerian medical colleges.

Unique contribution to theory, practice and policy: There is scarcity of literature on the intercalated degree programme in Nigeria. This research may influence policy change that will improve medical education. From the results of the study, it is recommended that the stakeholders in medical education should consider giving accreditation to more medical colleges that have the capacity to commence intercalated medical degree programs in Nigerian Universities as an option to interested medical students with good potentials.
\end{abstract}

Key words: Medicine, surgery, education, Intercalated, Science. 
American Journal of Health, Medicine and Nursing Practice

ISSN 2520-4017 (Online)

Vol.5, Issue 2 No.4, pp 83 - 91, 2020

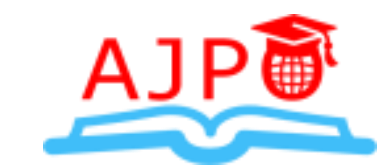

www.ajpojournals.org

\section{INTRODUCTION}

\subsection{Background of the study}

The intercalated degree is an extra year's study usually inserted between the second and third years of the medical course with the aim of studying a subject at greater depth and gaining a BSc, BA, or BMedSci degree (Agha et al., 2017). Student participation in research during medical school has been shown to promote a future interest in research. Therefore, to promote clinical research, it is important to evaluate educational pathways and the impediments to students undertaking research at medical school (Anderson, E. M., Johnston, K., Gunnarsson, R., \& Larkins, S., 2018).The origin of medical education in Nigeria can be traced from Yaba Higher College in the 1930s to the establishment of University College hospital Ibadan in 1948. From this modest beginning, there were 30 fully or partially accredited Medical schools in Nigeria as of 2010 (Federal Ministry Of Health-Health Systems Nigeria, 2012). Global changes in methods of medical instruction notwithstanding, it is difficult, indeed unwise to wholly adopt curricula designed by medical schools in advanced countries for use in sub-Saharan Africa. This is because there are remarkable differences between developed and developing nations in the quantity and quality of manpower and infrastructure on which these methods depend. Also of significance is the fact that intake into Nigerian medical and dental schools is at post secondary- school certificate level compared with graduate students in most western countries. This difference in level of knowledge, skills and attitude of necessity means that Nigerian students are less mature learners, which must be taken into consideration when teaching and assessment methods are being selected (Medical and Dental Council of Nigeria, 2006).

Approximately a third of UK medical students undertake a one year intercalated degree, usually a BSc in addition to their MBChB degree (Nicholson J.A., Cleland, J., Lemon, J. \& Galley, H.F., 2010). Studies have investigated the academic benefits of doing an additional degree, with suggestions that it may improve exam results in subsequent years. While an improved performance on exams may be perceived as a short-term benefit, this may actually have far greater significance (Mahesan, N., Crichton, S., Sewell, H. \& Howell S., 2011). Research has shown that students who take intercalated degrees are likely to have more papers published in scientific journals, and to have gained research grants (Eaton \& Thong, 1985, Stubbs T. A., Lightman, E.G. \& Mathieson, P., 2013). The most common reasons students have opted not to intercalate are: the cost and the extra year of study (Nicholson, J.A., Cleland, J., Lemon, J. \& Galley, H.F., 2010).

\subsection{Problem Statement}

Medical education is an insatiable field world over. In a developing country such as Nigeria, the high demand for medical education is faced with inadequate training man power and other needs for effective teaching. There is scarcity of researches with regards to intercalated MBBS degree program in Nigeria, a programme that may have a role in improving the outcome of medical school graduates. 
American Journal of Health, Medicine and Nursing Practice

ISSN 2520-4017 (Online)

Vol.5, Issue 2 No.4, pp 83 - 91, 2020

www.ajpojournals.org

\subsection{Research Objective}

The purpose of this study was to determine the level of awareness among academic staff of medical colleges about the program, to determine its acceptability and its possible merits and demerits, so as to make recommendations to stake holders of health education.

\section{MATERIALS AND METHODS}

\subsection{Study Design:}

It was a descriptive cross sectional survey.

Study tools/Materials: One hundred and fifty semi structured questionnaires

2.2 Target population: Academic staff of Nigerian Universities

2.3 Sample size: The acceptable minimum sample size for a survey to give meaningful results is 100 . Due to time constraints and limited resources, a sample size of 150 was chosen to improve the precision of the findings.

2.4 Sampling technique: Simple Random sampling was used

\subsection{Data Collection:}

The questionnaires were prepared, piloted and randomly administered to 150 participants who are academic staff of medical colleges in various universities spread across in Nigeria, who were attending an educational workshop at Abuja and who consented to participate in the study. One hundred and thirty eight questionnaires were successfully retrieved with a retrieval rate of $92 \%$.

\subsection{Data Analysis:}

The data was analyzed using Microsoft excel and calculated in percentages to ease comparison.

\section{RESULTS}

\section{Table 1}

Question 1: What do you understand by intercalated MBBS/BDS program?

\begin{tabular}{lcc}
\hline Response & Number of respondents(n) & Percentage (\%) \\
\hline B.Sc. with MBBS & 90 & 65 \\
No Idea & 48 & 35 \\
Total & $\mathbf{1 3 8}$ & $\mathbf{1 0 0}$ \\
\hline
\end{tabular}


American Journal of Health, Medicine and Nursing Practice

ISSN 2520-4017 (Online)

Vol.5, Issue 2 No.4, pp 83 - 91, 2020

www.ajpojournals.org

\section{Table 2}

Question 2: Do you offer intercalated degrees in your institution?

\begin{tabular}{lcc}
\hline Response & Number of respondents(n) & Percentage (\%) \\
\hline Yes & 90 & 65 \\
No & 48 & 35 \\
Total & 138 & 100 \\
\hline
\end{tabular}

Out of the 138 respondents, 90 respondents (65\%) say it is concurrent MBBS and a B.Sc. degree program and offer it in their institution while 48 Respondents (35\%) have no idea about intercalated MBBS program and do not offer it [Tables 1and 2]

\section{Table 3}

Question 3: Which University are you from?

\begin{tabular}{lll}
\hline & Number of respondents(N & Percentage $(\%)$ \\
\cline { 2 - 3 } North West & 15 & 11 \\
North East & 3 & 2 \\
North Central & 21 & 15 \\
South West & 30 & 22 \\
South East & 24 & 17 \\
South & 30 & 22 \\
Not answered & 15 & 11 \\
\hline Total & 138 & 100 \\
\hline
\end{tabular}


American Journal of Health, Medicine and Nursing Practice

ISSN 2520-4017 (Online)

Vol.5, Issue 2 No.4, pp 83 - 91, 2020

www.ajpojournals.org

\section{Which University/Institution are you from?}

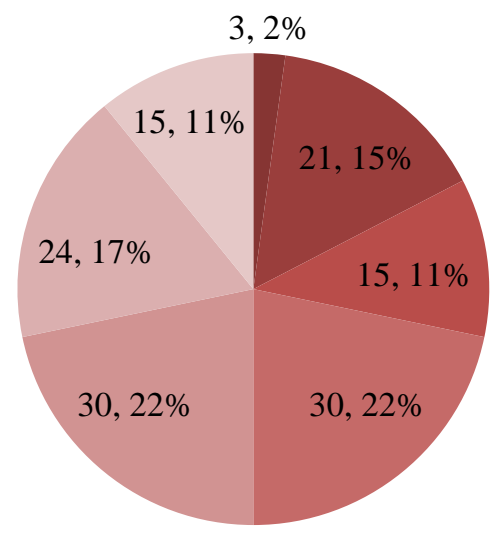

$\square \mathrm{NE}$

$\square \mathrm{NC}$

$\square \mathrm{S}$

nW

$\square \mathrm{SW}$

$\square \mathrm{SE}$

Not Answered

\section{Figure 1: Geographical distribution of the respondents' Universities}

Fifteen percent of the respondents are from Universities located in the North central(NC), $11 \%$ from the North West(NW),22\% from South West(SW) and $22 \%$ From the South, $12 \%$ South East and 11\% did not indicate their institution. [Table 3 , Figure 1]

Table 4

\begin{tabular}{|c|c|c|c|c|c|}
\hline \multirow[t]{2}{*}{ Questions } & \multicolumn{4}{|c|}{ Responses } & \multirow[t]{2}{*}{ Total } \\
\hline & Yes & No & Undecided & Unanswered & \\
\hline $\begin{array}{l}\text { Question 5: Do you believe that } \\
\text { intercalation in MBBS undergraduate } \\
\text { training is a way forward }\end{array}$ & 93 & 33 & 9 & 3 & 138 \\
\hline $\begin{array}{l}\text { Question 6: Do you think we should } \\
\text { adopt the new MBBS/BDS curriculum }\end{array}$ & 99 & 27 & 6 & 6 & 138 \\
\hline
\end{tabular}

Ninety three out of one hundred and thirty eight respondents believe that intercalated degrees is a way forward for future medical Education, 33 believe to be contrary, 9 were undecided and 3 did not answer the question. Ninety nine respondents think that the new BMAS document, which contains an option for the Intercalated degree should be adopted while 27 think it should not be adopted, 6 were undecided and 6 did not answer the question. 
American Journal of Health, Medicine and Nursing Practice

ISSN 2520-4017 (Online)

Vol.5, Issue 2 No.4, pp 83 - 91, 2020

www.ajpojournals.org

9. What do you think will be the advantage of this intercalation?

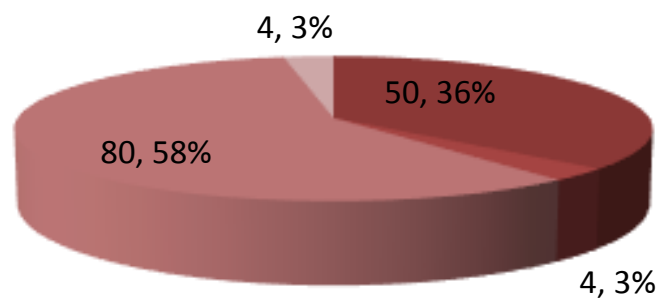

Having more experienced medical doctors in terms of research

Having another degree at hand

Both experience in research and additional degree

Exit alternative degree for medical students who want to leave MBBS

\section{Figure 2: Advantages of intercalation}

Thirty six percent of the respondents believe that the advantage of having Intercalated degrees is that more experienced medical doctors in terms of research will be produced. Another 3\% believe that having additional degree at hand is the advantage. 58\% report both experience in research and having additional degree as advantages while $3 \%$ reported the advantage as provision of exit point for students who wish to change from MBBS to BSc Degree program.

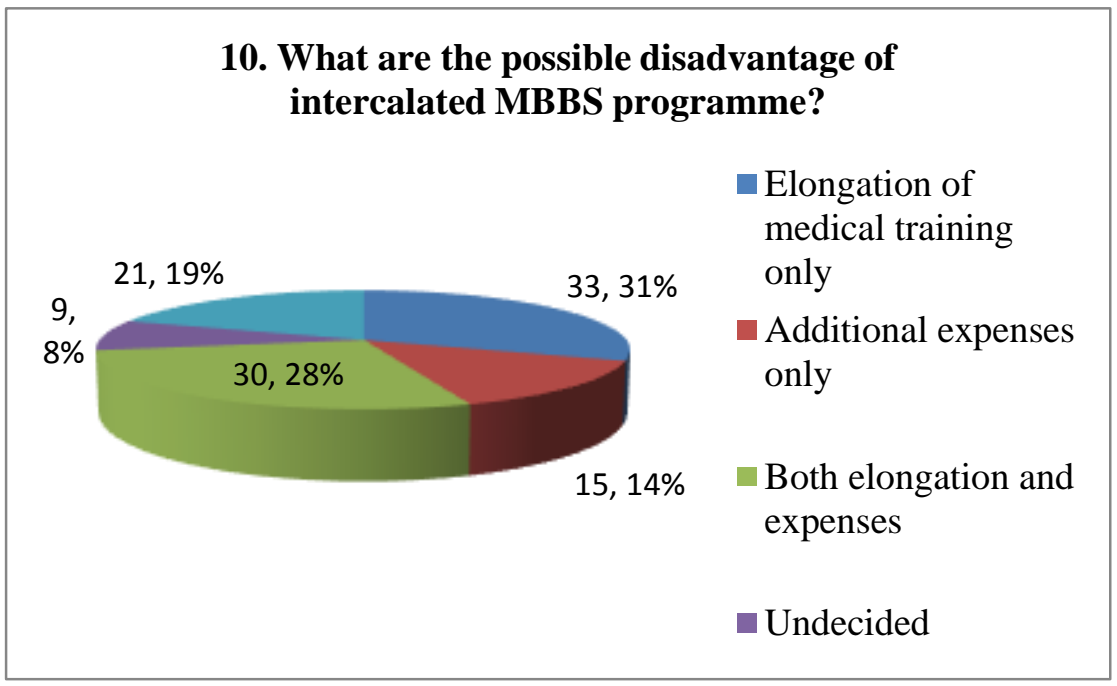

Figure 3: Disadvantages of intercalated MBBS Degree program 
American Journal of Health, Medicine and Nursing Practice

ISSN 2520-4017 (Online)

Vol.5, Issue 2 No.4, pp 83 - 91, 2020

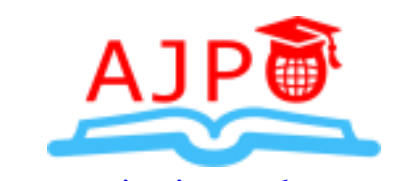

www.ajpojournals.org

Elongation of medical training duration was the major disadvantage reported by 33 respondents $(31 \%)$, additional expenses only was reported by15 respondents $(14 \%)$ respondents,30 respondents(28\%) reported both elongation and expenses as the disadvantages, 9(8\%) were undecided while 21(19\%) did not answer the question.

\section{DISCUSSION}

Intercalated Degrees may lead to more efficient utilization of man power through production of doctors that can perform dual roles. The dual roles include both teaching and research in the basic medical sciences while also contributing to clinical practice. More medical doctors are critically needed to perform both of these roles in Nigeria. The inadequacy of these categories of manpower has been a great limiting factor to the establishment and maintenance of medical colleges in Nigeria.

The respondents were distributed across the different geo-political zones in Nigeria (Table 3, figure 1). There was scarcity of data concerning the intercalated degree program in Nigeria. The new Benchmark Minimum Academic Standard (BMAS), which is an NUC document has come with a curriculum that may be used to kick start intercalated degrees in many medical colleges in Nigeria.

The finding in this study (Figure 7), that the advantage of having Intercalated degrees is having more experienced medical doctors in terms of research will be produced, is in keeping with findings of Eaton and Thong (1985) and that of Stubbs TA et al (2013). Elongation of medical training and extra cost reported as disadvantages of intercalation was also reported by Nicholson JA et al (2010). Intercalated BScs may improve undergraduate performance and increase the likelihood of pursuing academic careers, and are associated with a reduced likelihood of following a general practitioner career (Jones et al., 2013). They help students to develop reflexivity and key skills, such as a better understanding of critical appraisal and research (Jones et al., 2013). Similarly, another study Al-Busaidi (2020) suggests that completing an intercalated degree is associated with lower odds of pursuing a career in general practice. The findings highlighted the longer term value of an intercalated degree programme with particular emphasis on academic and personal skills; research and teaching skills; independence and confidence; its impact on future practice and the notion that 'student as teacher' programmes are a valuable asset to medical education as a whole (Muir et al., 2020). In a study involving students and supervisors, Students report the acquisition of a range of clinical, academic, and inter-professional skills following their intercalated BSc year. A positive experience was reported by supervisors, extending to host institutions (Graham et al., 2019). Other options of intercalation in medical colleges also exist in more advanced countries.

\section{CONCLUSION}

The expanded application of the Intercalated medical degree programme in more medical colleges has advantages with regards to boosting the manpower in the health care delivery and health education sectors. Most of the respondents were aware of the intercalated (dual) Bachelor of Medicine, Bachelor of Surgery (MBBS)/ Bachelor of Science (B.Sc.) degree programme, offer it in their institutions and believe it is 
American Journal of Health, Medicine and Nursing Practice

ISSN 2520-4017 (Online)

Vol.5, Issue 2 No.4, pp 83 - 91, 2020

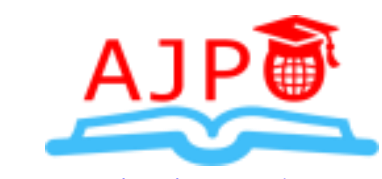

www.ajpojournals.org

worthwhile. Additional merits of the dual degree programme reported from this study included having an additional degree, more experienced medical doctors in terms of research; and a possible exit strategy for some medical students who may change their minds half way into the medical programme. The disadvantages reported were prolonged study period and increased cost of study. Majority of the respondents favoured the establishment of intercalated MBBS degree programme in more Nigerian medical colleges.

\section{RECOMMENDATION}

It is recommended that the stakeholders in medical education should consider giving accreditation to more medical colleges that have the capacity to commence intercalated medical degree programs in Nigerian Universities as an option to interested medical students with good potentials.

\section{References}

Agha, R., Fowler, A., Whitehurst, K., Rajmohan, S., Gundogan, B., \& Koshy, K., (2017b). Why apply for an intercalated research degree? International Journal of Surgery Oncology, 2(6), e27. https://doi.org/10.1097/ij9.0000000000000027

Alamri Y, Magner K. \& Wilkinson TJ.(2019). Would you do it again? A qualitative study of student and supervisor perceptions of an intercalated $\mathrm{MBChB} / \mathrm{PhD}$ programme. BMC Med Educ, 19(1):471. Published 2019 Dec 26. doi:10.1186/s12909-019-1909-z

Al-Busaidi, I. S. (2020). Effect of an intercalated research degree on general practice careers: a matched cohort study. Journal of Primary Health Care, 12 (2), 159 https://doi.org/10.1071/hc19097

Anderson, E. M., Johnston, K., Gunnarsson, R., \& Larkins, S., (2018a). Perceptions of a research honours programme embedded in a Bachelor of Medicine, Bachelor of Surgery degree: "The worst and best years of my life." Focus on Health Professional Education: A Multi-Professional Journal, 19(1), 1. https://doi.org/10.11157/fohpe.v19i1.144

Eaton, D. G., \& Thong, Y. H. (1985). The Bachelor of Medical Science research degree as a start for clinician-scientists. Medical Education, 19(6), 445-451. https://doi.org/10.1111/j.1365-2923.1985.tb01352.x

Federal Ministry of Health of Nigeria, Health Systems 20/20 Project. (2012). Nigeria Undergraduate Medical and Dental Curriculum Template, 2012, Bethesda, MD: Health Systems 20/20 project, Abt Associates Inc.

Graham, B., Elbeltagi, H., Nelmes, P., Jenkin, A. \& Smith, ,J. (2019).What difference can a year make? Findings from a survey exploring student, alumni and supervisor experiences of an intercalated degree in emergency care. BMC Med Educ 19, 188 https://doi.org/10.1186/s12909-019-1579-x 
Jones, M., Hutt, P., Eastwood, S. \& Singh, S., (2013). Impact of an intercalated BSc on medical student performance and careers: A BEME systematic review: BEME Guide No. 28. Medical Teacher, 35(10), e1493-e1510. https://doi.org/10.3109/0142159x.2013.806983

Kwan JM, Daye D, Schmidt ML \& Conlon CM., (2017). Exploring intentions of physician-scientist trainees: factors influencing $\mathrm{MD}$ and $\mathrm{MD} / \mathrm{PhD}$ interest in research careers. BMC Med Educ. 17(1):115. Published 2017 Jul 11. https://doi.org/10.1186/s12909-017-0954-8

Mahesan, N., Crichton, S., Sewell, H. \& Howell S., (2011). The effect of an intercalated BSc on subsequent academic performance. BMC Med Educ 11, 76. https://doi.org/10.1186/1472-6920-11-76

MDCN, Medical and Dental Council of Nigeria. (2006). The Red Book: Guidelines on Minimum Standard of Medical and dental Education in Nigeria, Abuja, Nigeria. Available from: http//www.mdcnigeria.org.

Muir, F., Bruce, J., \& McConville, K. (2020). Teaching, reflecting, and learning: The value of an intercalated medical education programme. Medical Teacher, 42(5), 523-528. https://doi.org/10.1080/0142159x.2019.1708290

Nicholson, J.A., Cleland, J., Lemon, J. \& Galley, H.F. (2010). Why medical students choose not to carry out an intercalated BSc: a questionnaire study. BMC Med Educ 10, 25. https://doi.org/10.1186/1472-6920-10-25.

Stubbs, T. A., Lightman, E.G. \& Mathieson, P. (2013). Is it intelligent to intercalate? A two centre cross-sectional study exploring the value of intercalated degrees, and the possible effects of the recent tuition fee rise in England. BMJ Open, 3(1), e002193. https://doi.org/10.1136/bmjopen-2012-002193 